\title{
Identification of c-fos-responsive Elements Downstream of TAR in the Long Terminal Repeat of Human Immunodeficiency Virus Type-1
}

Kenneth A. Roebuck, David A. Brenner, and Martin F. Kagnoff

Department of Medicine, University of California, San Diego, La Jolla, California 92093-0623

\begin{abstract}
Activation of HIV-1 requires the binding of host cell transcription factors to cis elements in the proviral long terminal repeat (LTR). This study identifies c-fos-responsive sequence motifs in the U5 transcribed noncoding leader sequences downstream of the viral transactivator responsive (TAR) element. These DNA sequence motifs are the most downstream regulatory elements described thus far in the HIV-1 LTR. Functional studies, using human colon epithelial cell lines, demonstrate that the downstream elements are transactivated by expression of the c-fos protooncogene and can transmit PMA and TNF $\alpha$ activation signals to the viral LTR. Moreover, the c-fos-responsive elements mediate HIV-1 LTR transcription independent of Tat and the $N_{K} B$-binding enhancer element. Nuclear extracts of colon epithelial cells form distinct gel mobility shift complexes with the c-fos-responsive elements. These complexes comigrate with a gel shift complex formed on a classical CRE oligonucleotide and are competed by CRE oligonucleotides. These data indicate that the HIV-1 LTR contains previously unrecognized functional DNA cis-regulatory elements downstream of TAR in the transcribed noncoding $5^{\prime}$ leader sequence and suggest that early response genes such as c-fos play a role in the activation of HIV-1 gene expression. (J. Clin. Invest. 1993. 92:1336-1348.) Key words: oncogenes • transcription factors • epithelial cells $\bullet$ activator protein-1 $\bullet$ untranslated 5 ' leader
\end{abstract}

\section{Introduction}

HIV-1 is the etiological agent of $\operatorname{AIDS}(1,2)$. After HIV-1 integrates into the host genome as latent proviral DNA, a threshold burst of genomic length transcription is required to complete the viral life cycle and produce progeny virus (3). This initial transcription of the HIV-1 genome is controlled by the $5^{\prime}$ long terminal repeat (LTR) ${ }^{1}$ and is dependent upon host cellular transcription factors binding to a series of DNA regula-

Address correspondence and reprint requests to Martin F. Kagnoff, M.D., Department of Medicine, 0623D, University of California, San Diego, 9500 Gilman Drive, La Jolla, CA 92093. K. A. Roebuck's present address is the Department of Immunology/Microbiology, RushPresbyterian-St. Luke's Medical Center, 1653 West Congress Parkway, Chicago, IL 60612. D. A. Brenner's present address is the Department of Medicine, University of North Carolina, CB \#7080, Room 326, Burnett-Womack Building, Chapel Hill, NC 27599.

Received for publication 7 December 1992 and in revised form 14 April 1993.

J. Clin. Invest.

(c) The American Society for Clinical Investigation, Inc. $0021-9738 / 93 / 09 / 1336 / 13 \$ 2.00$

Volume 92, September 1993, 1336-1348 tory elements in the LTR promoter (4). Transcriptional studies of the HIV-1 genome indicate that the HIV-1 LTR promoter can be subdivided into three functional domains: a basal core promoter, which is comprised of the transcriptional start site, a TATA box, and three tandem Spl binding sites (GCboxes); an upstream enhancer element containing two adjacent binding sites for the inducible transcriptional activator nuclear factor kappa B (NF $\mathrm{B})$; and a far upstream modulatory region $(4,5)$. The HIV-1 LTR promoter also contains several recognition sites for nucleic acid binding proteins downstream of the transcriptional start site (6). However, with the exception of the transactivator responsive (TAR) element, which, upon transcription into a specific RNA structure, binds the viral transactivator protein Tat, the importance of these downstream sequence motifs or their role in HIV-1 gene expression has not been demonstrated.

HIV-1 is associated with disease of the immune, nervous, and digestive systems $(1,7,8)$. Infected epithelial and other cell types in the gastrointestinal tract are potential reservoirs of HIV-1 and may contribute to the pathophysiology of diarrheal syndromes in HIV-1-infected individuals (9-17). Recently, we reported differences among three human colonic epithelial cell lines, SW620, HT29, and T84, with respect to their expression of the CD4 / HIV-1 receptor, HIV-1 infectivity and replication, and activation of the HIV-1 LTR by protein kinase C (PKC) activators (18). Thus, transcriptional activation of the HIV-1 LTR was stimulated by phorbol esters (phorbol 12myristate 13-acetate [PMA]) and the proinflammatory cytokine TNF $\alpha$ in the HIV-1 infectible SW620 and HT29 cell lines, but not in the noninfectible T84 colon epithelial cell line (18). Although mutational analysis indicated that increased transcriptional activity of the HIV-1 LTR in SW620 and HT29 cells was due, at least in part, to activation of the $\mathrm{NF}_{\kappa} \mathrm{B}$-binding enhancer elements (18), the same agonists are also known to activate other sequence-specific DNA binding proteins, including the transcription factor activator protein-1 (AP-1) (19).

AP-1 is a member of a class of DNA binding proteins encoded by a multigene family of nuclear protooncogenes that mediate cellular responses to growth factors, regulatory cytokines, and tumor-promoting PMA via an AP-1 binding site, termed a TRE (for TPA/PMA-responsive element) (19-23). The AP-1 binding site or TRE is recognized by dimeric protein complexes composed of Jun homodimers or Jun/Fos heterodimers $(19,24)$. The Fos component of AP-1 does not itself

1. Abbreviations used in this paper: AP-1, activator protein-1; ATF, activating transcription factor; CAT, chloramphenicol acetyltransferase; CRE, cAMP responsive element; CREB, CRE binding protein; DSE, downstream sequence element; LTR, long terminal repeat; NF $K$ B, nuclear factor kappa B; PIE, PMA inhibitory element; TAR, transactivator responsive; TPA, 12-0-tetradecanoylphorbol-13-acetate TRE, TPA/PMA responsive element. 
bind the TRE because of an inability to form homodimers, but in the presence of Jun, Fos forms a Fos/Jun heterodimer complex of greater stability than Jun/Jun homodimers (25-27). Several TRE-like motifs, some of which bind c-Fos-containing complexes, have been identified in the upstream modulatory region of the HIV-1 LTR $(24,28)$. However, a functional role for c-Fos or AP-1 in either positive or negative regulation of HIV-1 gene expression has not been demonstrated.

The cAMP-responsive element (CRE) binding protein/activating transcription factor (CREB/ATF) family of cellular transcription factors is a closely related class of transcription factors with members that are structurally similar to members of the Jun/Fos family. Like Jun/Fos family members, CREB/ ATF family members can also interact with each other to form dimers that recognize the CRE, a sequence similar to the TPA/ PMA responsive element (TRE) (29-31). Recent studies have shown that members of the Jun/Fos family can combine with certain members of the CREB/ATF family, via their leucine zipper dimerization domains, to form cross-family heterodimers that preferentially bind to CRE-like motifs (32-35). For example, c-Fos and c-Jun can cross-combine with several different ATF transcription factors (36). The ability to form such cross-family dimers increases the repertoire of protein factors available for gene regulation.

In this study, we identify functional TRE/CRE-like sequence motifs within the U5 region of the HIV-1 LTR. Expression studies in human colon epithelial cell lines indicate that TRE/CRE-like downstream sequence elements (DSE) can mediate transcription of the HIV-1 LTR in the absence of a functional HIV-1 enhancer element and independent of Tat transactivation. These DSE sites are transactivated by the c-fos nuclear protooncogene and can transmit PMA and TNF $\alpha$ activation signals to the HIV-1 LTR in HIV-1 infectible, but not in noninfectible, colon epithelial cell lines. DNA binding studies show that nuclear extracts from colon epithelial cells form c-Fos-containing gel shift complexes with the TRE/ CRE-like DSE that are also recognized by classical CRE motifs.

\section{Methods}

Plasmids and synthetic deoxyoligonucleotides. The HIV-1 -91/+232 LTR chloramphenicol acetyltransferase (CAT) reporter plasmid was previously described (37). It consists of $91 \mathrm{bp}$ of HIV-1 LTR sequences upstream of the transcriptional initiation site $(+1)$ and $232 \mathrm{bp}$ of LTR sequences downstream of transcription, extending into the U5 region of the LTR, linked to a CAT reporter gene. The $-91 /+232 \Delta$ S LTR CAT plasmid was derived from the $-91 /+232$ construction by excis- ing an internal $183 \mathrm{bp} \mathrm{SstI} \mathrm{fragment} \mathrm{from} \mathrm{nucleotide} \mathrm{position}+39$ to +222. The $-91 /+232$ M6 LTR CAT plasmid was constructed in two steps by using cassette mutagenesis. In the first step, an interim mutational plasmid ( $\mathrm{pBS}-\mathrm{HIV}-\mathrm{SstIM}$ ) was constructed by cloning a mutant oligonucleotide cassette into a pBluescript II vector (Stratagene, Inc., San Diego, CA) to yield a plasmid containing LTR wild-type sequences from +39 to +222 except for several point mutations around +160 and +95. The base pair changes (see Fig. $3 A$ ) introduced into the two motifs were designed to create two new restriction enzyme recognition sites, a BssHII site at +160 and a NotI site at +95 , as well as disrupt the nucleotide sequence homologies to TRE and CRE motifs in those regions. These mutations also do not appreciably alter the predicted RNA secondary structure of the transcribed noncoding $5^{\prime}$ leader sequence. Mutations in pBS-HIV-SstIM were identified by restriction digestions with BssHII and NotI and were verified by dideoxynucleotide sequencing. For the second step of the mutagenesis, a 183-bp SstI restriction fragment from pBS-HIV-SstIM was cloned back into its original HIV-1 context to obtain the $-91 /+232$ M6 LTR CAT reporter plasmid ( see Fig. $3 \mathrm{~A}$ ). The correct transcriptional orientation of the cloned fragment in the $-91 /+232 \mathrm{M} 6$ plasmid was determined by restriction analysis and confirmed functionally with a Tat cotransfection assay (see Fig. $3 B$ ).

The expression plasmids RSV-c-jun, SV-c-fos, SV-fosB, RSV$j u n B$, and RSV-NF1 have been described previously $(20,28,38,39)$. The SV-tat expression plasmid, provided by A. B. Rabson (Center for Advanced Biotechnology and Medicine, Piscataway, NJ), contains the first exon of the HIV-1 tat gene driven by the SV40 early promoter (40). The HIV-1 firefly luciferase reporter gene plasmid (HIV-1LUC), provided by A. Siddiqui (University of Colorado, Denver), contains complete LTR promoter sequences upstream of $+80(41)$. The TRE luciferase reporter gene plasmid (TRE/AP-1-LUC), provided by M. G. Rosenfeld (University of California, San Diego), consists of two pairs of consensus TRE motifs upstream of a rat prolactin minimal promoter containing a TATA box (see Fig. $5 A$ ) (42). Plasmids used as negative controls (e.g., RSV- $\beta$ gal, SV- $\beta$ gal, and RSV-neo) were described previously (43).

Deoxyoligonucleotides were synthesized using a Milligen DNA synthesizer (Millipore Corp., Novato, CA) and purified as specified by the manufacturer. The Spl and NF1 oligonucleotides were described previously (39). Other oligonucleotides used in these studies are listed in Table I. To produce DNA gel shift probes, oligonucleotides were made double stranded by annealing the single-stranded complementary oligonucleotides and end labeling with $\left[\gamma^{32} \mathrm{P}\right] \operatorname{ATP}(3,000 \mathrm{Ci} / \mathrm{mmol})$ and T4 polynucleotide kinase.

Cell culture, transient transfections, and reporter gene assays. Human colon epithelial cell lines SW620, HT29, and T84 were obtained, maintained, and transfected as previously described (18). For stimulation, cells were treated $16-20 \mathrm{~h}$ after transfection with optimal concentrations of human recombinant TNF $\alpha(20 \mathrm{ng} / \mathrm{ml})$ (Genentech Inc., South San Francisco, CA) or PMA ( $20 \mathrm{ng} / \mathrm{ml}$ ) (Sigma Chemical Co., St. Louis, MO) for 16 to $20 \mathrm{~h}$. CAT (EC 2.3.1.28) and firefly luciferase

Table I. Synthetic Deoxyoligonucleotides Used to Detect DNA Binding Activities

\begin{tabular}{llll}
\hline Oligo* & Source & Position $^{*}$ & \multicolumn{1}{c}{ Sequence $^{s}$} \\
+95 & HIV DSE-1 & $+84 /+105$ & GCCTTGAGTGCTTCAAGTAGTG \\
+160 & HIV DSE-2 & $+149 /+170$ & GACCTTTTAGTCAGTGTGGAA \\
$+160 \mathrm{M}$ & HIV DSE-2 & $+149 /+170$ & GACCCTTGGGGCGGGTGTGGAA \\
TRE & Collagenase & $-79 /-58$ & TAAAGCA $\underline{\text { TGAGTCAGACACCTC }}$ \\
CRE & Somatostatin & $-58 /-37$ & CCTTGGCTGACGTCAGAGAGAG \\
PIE & Collagen & $-732 /-707$ & GCCACACACTGAGTTCACCTAGGT
\end{tabular}

* The nontemplate strand is shown. ${ }^{*}$ Relative to the transcriptional initiation site $(+1) .{ }^{8}$ Mutated sequences and sequences homologous to TRE and CRE consensus motifs are underlined. TRE, TPA/PMA-responsive element; CRE, cAMP-responsive element; PIE, phorbol ester inhibitory element. 
A

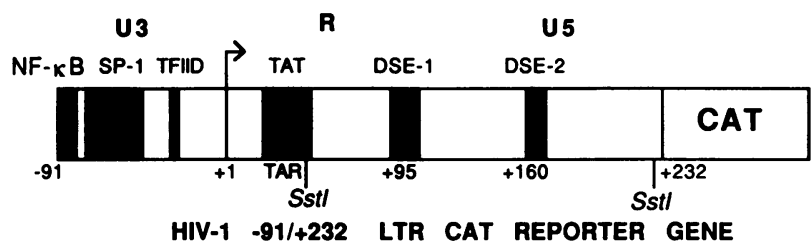

B
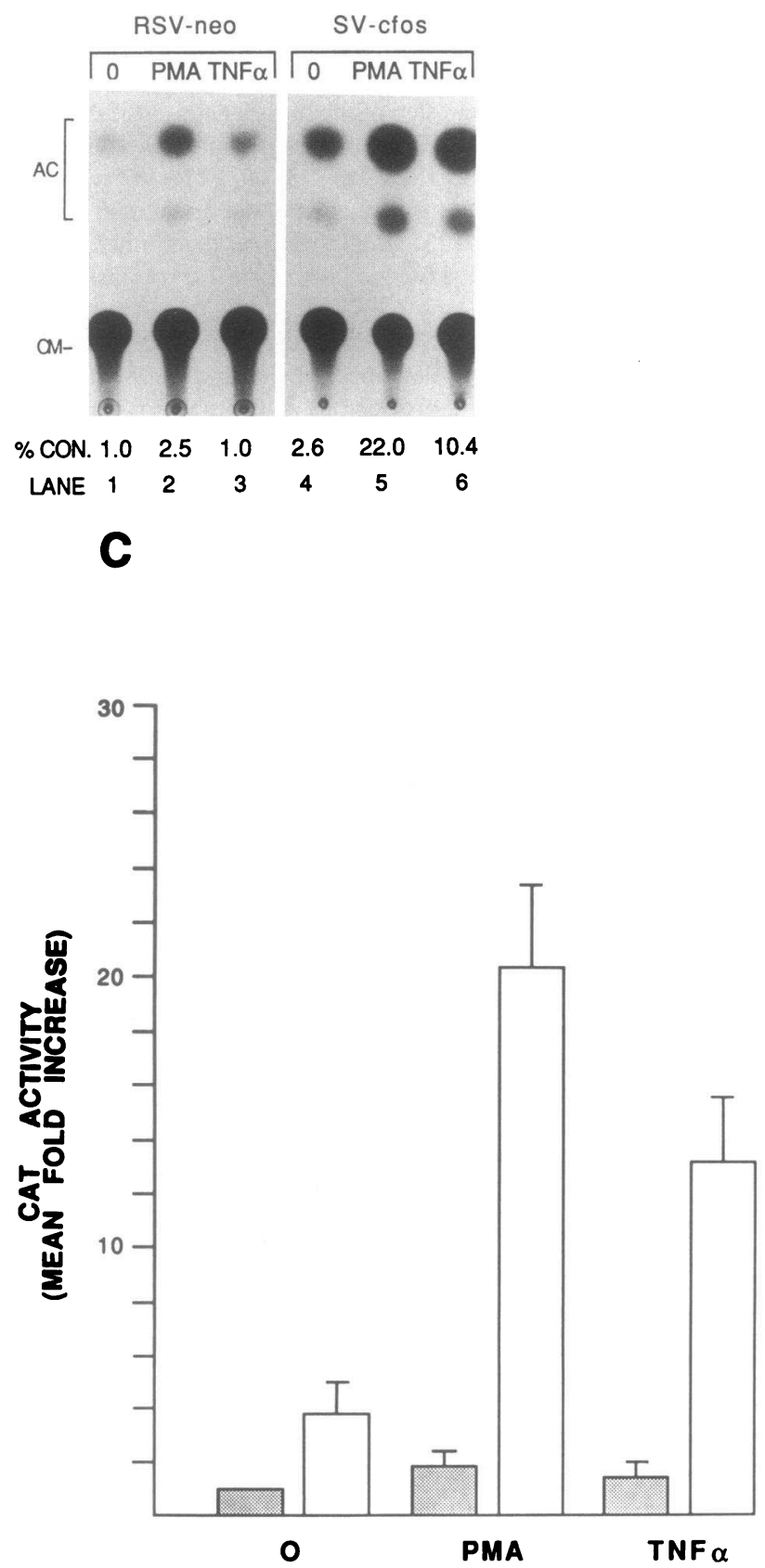

Figure 1. Effect of c-fos expression on HIV-1 LTR-mediated gene transcription in PMA- or TNF $\alpha$-activated SW620 colon epithelial cells. $(A)$ Structure of the HIV-1 $-91 /+232$ LTR CAT construction. Binding sites (solid boxes) for known viral (TAT) and cellular factors $\left(N F_{K} B, S P 1\right.$, and $\left.T F I I D\right)$ are indicated in relation to the $\mathrm{U} 3, \mathrm{R}$, and U5 viral LTR regions. The two newly identified c-fos-responsive DSE at +95 (DSE-1) and +160 (DSE-2) are also indicated. The po-
(EC 1.13.12.7) activity assays were performed on equivalent amounts of protein from cellular extracts and quantitated as described previously $(18,39,43)$. For comparisons between experiments, relative expression was measured by normalizing reporter gene activity to the CAT or luciferase activity produced by the same reporter gene coupled to the control expression plasmids RSV- $\beta$ gal or RSV-neo as indicated in the figures. RSV and SV both act as strong promoters in all three cell lines, as assayed in control cells transfected with RSV-luciferase or SV-luciferase.

DNA binding studies. Electrophoretic mobility shift assays were performed as described by Smeal et al. (26). Briefly, purified bacterially expressed trpE-c-Jun fusion protein $(10 \mathrm{ng} / \mu \mathrm{l})(26)$ or nuclear extracts ( 5-7 $\mu$ g protein $/ \mu \mathrm{l}$ ) prepared from colon epithelial cells by the method of Shapiro et al. (44) were incubated with $50,000 \mathrm{cpm}(\sim 0.5$ $\mathrm{ng}$ ) of various ${ }^{32} \mathrm{P}$-end-labeled HIV-1 LTR DNA or double-stranded synthetic deoxyoligonucleotide probes (Table I) for $30 \mathrm{~min}$ at $4^{\circ} \mathrm{C}$ in a $20-\mu$ l reaction volume containing $12 \%$ glycerol, $12 \mathrm{mM}$ Hepes- $\mathrm{NaOH}$ (pH 7.9), $60 \mathrm{mM} \mathrm{KCL}, 5 \mathrm{mM} \mathrm{MgCl} 2,4 \mathrm{mM}$ Tris-Cl (pH 7.9), 0.6

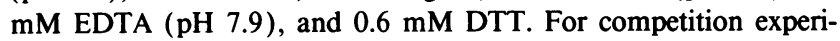
ments, 10 or $50 \mathrm{ng}$ of unlabeled deoxyoligonucleotide competitor ( $\sim 20$ - and 100 -fold excess competitor, respectively) was added to binding reactions before addition of extract. In experiments using cFos antibody, antibody was added to the binding reactions $10 \mathrm{~min}$ before the addition of the DNA probe. Protein-DNA complexes were resolved in 5\% native polyacrylamide gels preelectrophoresed for 1 to 2 $\mathrm{h}$ at $4^{\circ} \mathrm{C}$ in $0.25 \times \mathrm{TBE}$ buffer $(22.5 \mathrm{mM}$ Tris-borate and $0.5 \mathrm{mM}$ EDTA, $\mathrm{pH}$ 8.3). Gels were dried and exposed overnight to x-ray film (Eastman Kodak Co., Rochester, NY) with an intensifying screen at $-70^{\circ} \mathrm{C}$.

\section{Results}

c- Fos transactivates the HIV-1 LTR in colon epithelial cells treated with $P M A$ or $T N F \alpha$. Previous results indicated that TNF $\alpha$ and PMA activate the HIV-1 LTR through the NF $\kappa$ Bbinding sites in HIV-1 infectible, but not in noninfectible, human colon epithelial cells (18). However, for a full transcriptional response, it appeared that the $\mathrm{NF} \kappa \mathrm{B}$ binding sites, although necessary, were not sufficient and that LTR sequences in addition to the HIV-1 enhancer also contributed to these agonist responses (18). Since activators of PKC can induce, in

sition of the two SstI sites at +39 and +222 used to construct a deletion mutation plasmid are indicated. $(B)$ Transient transfections of the $-91 /+232$ LTR CAT construct in SW620 cells. $5 \mu \mathrm{g}$ of the $-91 /$ +232 LTR reporter plasmid was cotransfected with $5 \mu \mathrm{g}$ of either the control RSV-neo expression vector (lanes 1-3) or SV-c-fos (lanes 4-6). 16-20 h after transfection, some cells were treated with $20 \mathrm{ng}$ / ml of PMA (lanes 2 and 5) or TNF $\alpha$ (lanes 3 and 6 ), whereas other cells were untreated (lanes 1 and 4 ). CAT assays were performed using equivalent amounts of protein as described previously (18). For each transfection, the percent conversion (\% CON.), calculated by dividing the ${ }^{14} \mathrm{C}$ counts converted into acetylated chloramphenicol product $(A C)$ by the total ${ }^{14} \mathrm{C}$ counts $(\mathrm{AC}+\mathrm{CM})$ multiplied by 100 , is indicated below the corresponding lane. $(C)$ Quantitation of the c- fos transactivation response in SW620 cells. In four independent transfection experiments, SW620 cells were cotransfected with either a c-fos expression vector (open bars) or a control RSV- $\beta$ gal plasmid (stippled bars) together with the chimeric -91/+232 LTR CAT reporter gene. Cells were stimulated with PMA or TNF $\alpha$ or unstimulated as indicated. Height of the bars represent the mean fold increase of $-91 /+232$ LTR-directed CAT activity normalized to the CAT activity of the unstimulated RSV- $\beta$ gal expression plasmid control plus the standard error of the mean (SEM). In control experiments, the RSV and SV promoters were shown to be comparably active in SW620 cells. 
addition to $\mathrm{NF}_{\kappa} \mathrm{B} /$ rel, cellular factors in the Jun/Fos family of transcription factors, we asked whether AP-1 proteins play a role in transcriptional activation of the HIV-1 LTR. Several AP-1 binding sites had been identified before, upstream of the $\mathrm{NF}_{\kappa} \mathrm{B}$ binding sites, but a functional role for these motifs has thus far not been demonstrated $(24,28,45)$.

We describe herein that there also are previously unrecognized AP-1-like binding sites in the HIV-1 LTR downstream of the promoter in the transcribed noncoding $5^{\prime}$ leader sequence. At least two distinct regions, one centered at nucleotide position +95 and the other at +160 in the $5^{\prime}$ untranslated leader sequences downstream of TAR, exhibit a high degree of sequence similarity to classical TRE and CRE motifs (Fig. 1 $A$ ). To assess whether these newly recognized DSE might contribute to activation of the HIV-1 LTR, we performed transient cotransfection experiments with a truncated HIV-1 LTR reporter gene plasmid, $-91 /+232$ LTR CAT, which contains HIV-1 LTR sequences from nucleotide position -91 to +232 (relative to the viral transcription initiation site) coupled to a CAT reporter gene (Fig. $1 A$ ). Unlike LTR CAT constructions that contain upstream AP-1 binding sites and a functional HIV-1 enhancer element with two NF $\kappa$ B-binding sites, the $-91 /+232$ LTR CAT plasmid has only the $3^{\prime}$ NF $K$ B binding site intact and, compared with a construction with both $\mathrm{NF}_{\kappa} \mathrm{B}-$ binding sites (18), is only weakly expressed when cotransfected into SW620 cells with a control RSV-neo expression plasmid (Fig. $1 \mathrm{~B}$, lane 1 ). Consistent with our previous results, this enhancer mutant construction exhibited little or no response to the PKC activators PMA and TNF $\alpha$, respectively (Fig. $1 B$, lanes $1-3$ ).

As shown in Fig. 1, we first tested whether c-Fos, a major component of AP-1 complexes, could stimulate HIV-1 LTR gene transcription in the absence of an intact HIV-1 enhancer and upstream AP-1 binding sites. For these studies, the -91/ +232 reporter plasmid was cotransfected into the HIV-1 infectible colon epithelial cell line SW620, together with an expression vector that produces $c-F o s$. When the $-91 /+232$ reporter plasmid was cotransfected with the c-fos expression plasmid, HIV-1 LTR reporter gene activity increased (Fig. $1 \mathrm{~B}$, lane 4 compared with lane 1 ). Moreover, in c-fos-cotransfected cells, the $-91 /+232$ LTR reporter gene became highly responsive to both PMA and TNF $\alpha$ stimulation (Fig. $1 \mathrm{~B}$, lanes 5 and 6 ). c-Fos transactivation of the HIV-1 LTR reporter gene was quantitated in several independent transfection experiments. As shown in Fig. $1 C$, c-fos transfection increased HIV-1 LTR activation fourfold over controls (RSV- $\beta$ gal plasmid). In contrast, there was a mean 10-20-fold activation of the HIV-1 LTR when the c-fos-cotransfected cells were stimulated with PMA or TNF $\alpha$. The data shown in Fig. 1 demonstrate that an intact HIV-1 enhancer and upstream AP-1 binding sites are
HIV-1 -91/+232 LTR CAT REPORTER

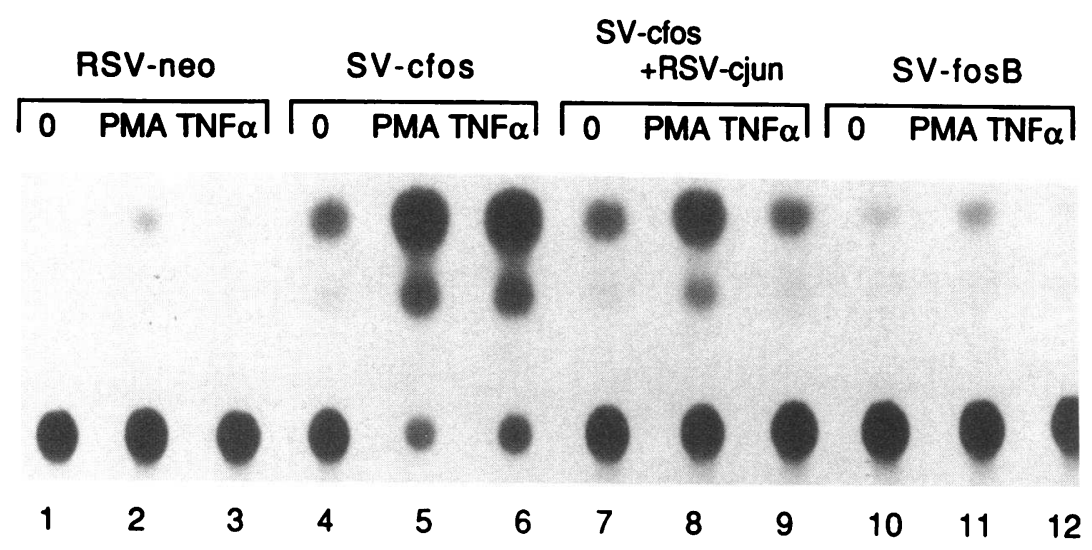

HIV-1 -91/+232 $\Delta \mathrm{S}$ LTR CAT REPORTER

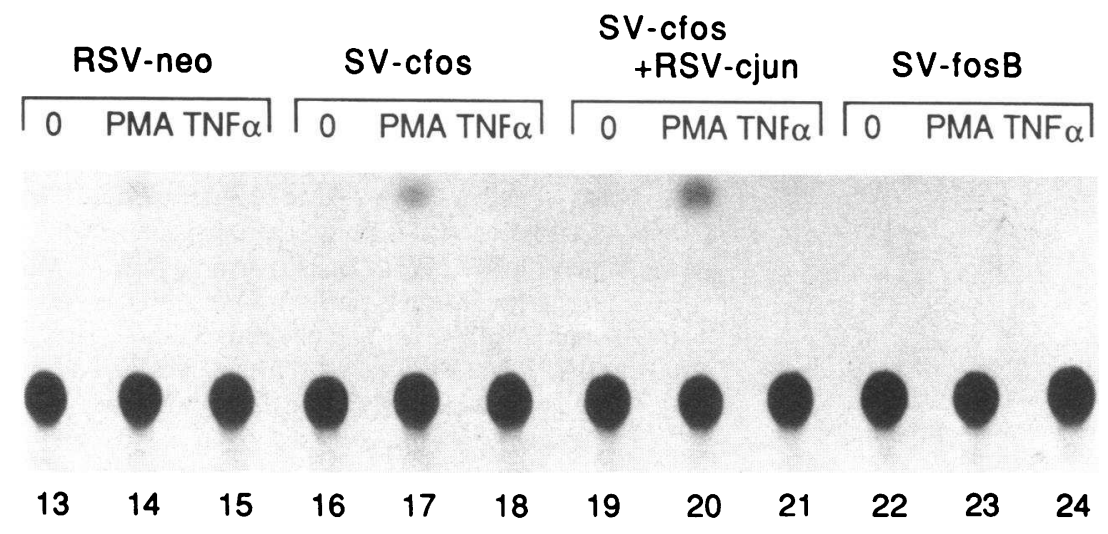

Figure 2. A deletion in the $-91 /+232$ LTR CAT plasmid abrogates c-fos transactivation of the HIV-1 LTR. Transfections and CAT assays were performed as described in Methods and the legend of Fig. 1. The top panel (lanes 1-12) shows results using the $-91 /+232$ construction transfected into SW620 cells. The bottom panel (lanes 13-24) shows parallel results with the $-91 /+232 \Delta$ S deletional mutation, which is identical in structure to the $-91 /+232$ plasmid except for the deletion of sequences between the two SstI sites at +39 and +222 (see Fig. $1 A$ ). Expression plasmids that were cotransfected and agonist $(P M A, 20 \mathrm{ng} / \mathrm{ml}$ and $T N F \alpha, 20 \mathrm{ng} / \mathrm{ml})$ treatments are indicated above each lane. 
not required for c-Fos transactivation of HIV-1 gene expression and indicate the c-Fos response is mediated by LTR sequences downstream of the HIV-1 enhancer. In further control experiments, using additional LTR constructions or proviral plasmids, it was shown that c-Fos transactivation of the HIV-1 LTR can also occur in the presence of a functional HIV-1 enhancer element, which contains both $\mathrm{NF}_{\kappa} \mathrm{B}$ binding sites (data not shown).

The HIV-1 LTR contains c-Fos-responsive elements downstream of TAR. The observation that c-Fos, in concert with PMA or TNF $\alpha$, stimulated HIV-1 LTR-mediated CAT activity suggested that the HIV-1 LTR contained a TRE or CRE element downstream of the HIV-1 enhancer. We first tested whether a deletion of the TRE/CRE-like LTR sequences encompassing the downstream TRE/CRE-like motifs centered at nucleotide positions +95 and +160 would alter the c-Fos transactivation effect documented in Fig. 1. The construction used had a deletion between two SstI restriction sites from +39 to +222 in the $-91 /+232$ LTR CAT construction. In cotransfection experiments (Fig. 2, top), the wild-type -91/ +232 construction, as indicated previously (Fig. 1), was transactivated by c-Fos in SW620 cells. In contrast, c-Fos transactivation of a similar construction lacking the downstream TRE/ CRE-like motifs $(-91 /+232 \Delta \mathrm{S})$ was significantly reduced (Fig. 2, compare lanes 4-6 and 16-18). The downstream deletion had no detectable effect on LTR-mediated CAT activity in the control RSV-neo plasmid cotransfections (compare lanes 1-3 and 13-15). These results indicate that LTR sequences downstream of TAR, between nucleotide positions +39 and +222 , are required for c-Fos transactivation of the HIV-1 reporter gene construct. In further experiments, cotransfection of the c-Jun expressing plasmid together with c-Fos did not restore the transactivation response in cells containing the -91 / $+232 \Delta S$ construct and, in fact, it attenuated the transcriptional response stimulated by TNF $\alpha$ and PMA in the c-Fos-transfected cells containing the wild-type $-91 /+232$ construct (Fig. 2, compare lanes 7-9 and 19-21). FosB, another member of the fos gene family (27), was unable to significantly stimulate LTR-ediated CAT activity in SW620 cells (see Fig. 2, lanes 10-12 and 22-24).

Point mutations in the +160 and +95 TRE/CRE-like motifs abrogate c-Fos transactivation of HIV-1 gene expression. To demonstrate whether the TRE/CRE-like motifs at +160 and +95 were important for c-Fos transactivation of the HIV-1 LTR, we introduced cluster point mutations into these DSE. Unlike the wild-type reporter gene (Fig. $3 \mathrm{~B}$, lanes 3 and 4), when the $-91 /+232 \mathrm{M} 6$ construction containing mutations in the +95 and +160 DSE motifs was transfected into SW620 cells, no detectable transactivation of the HIV-1 LTR was observed with cotransfection of a c-Fos-expressing plasmid in either untreated or PMA-treated cells (Fig. $3 \mathrm{~B}$, lanes 7 and 8 ). In contrast, a cotransfected Tat expression plasmid strongly stimulated the $-91 /+232 \mathrm{M} 6$ reporter gene construction in PMA-treated (Fig. 3, lane 9) and untreated SW620 colon epithelial cells (data not shown). The cluster mutations had little or no effect on the basal level of gene activity (compare lanes 1

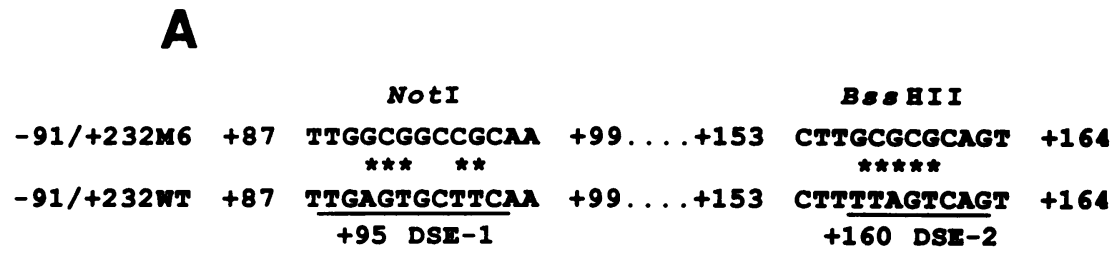

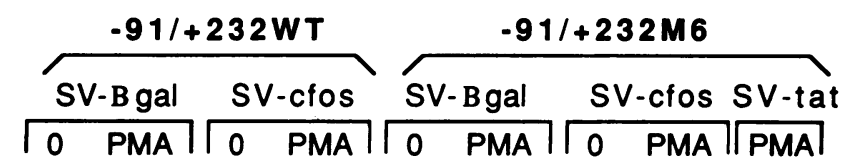

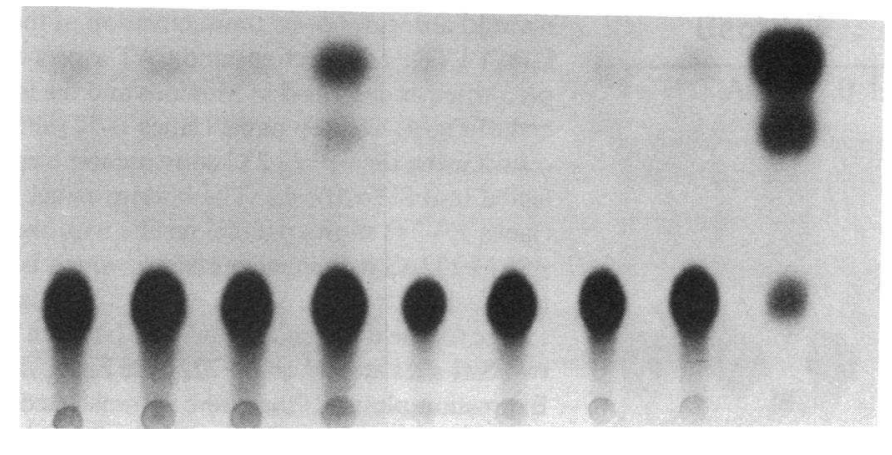

1
Figure 3. Effect of cluster point mutations in the HIV-1 DSE motifs on c- fos transactivation of the HIV-1 LTR. Transfections and CAT assays were performed as described in Methods and the legend of Fig. 1. (A) Mutations introduced into the $-91 /+232 \mathrm{WT}$ reporter construct at DSE-1 and DSE-2 by cassette mutagenesis are as described in Methods. Asterisks denote specific base pair changes from the wild type that create a NotI site at +95 and a BssHII site at +160 in the $-91 /+232 \mathrm{M} 6$ reporter plasmid. $(B)$ Expression results from experiments in which the $-91 /+232$ WT (lanes $1-4$ ) or $-91 /+232$ M6 reporter constructs (lanes 5-9) were transfected into SW620 cells. The plasmids SV-c-fos (lanes $3,4,7$, and 8), SV- $\beta$ gal (lanes $1,2,5$, and 6), and SV-tat (lane 9) cotransfected with the LTR reporter genes are indicated. CAT activity derived from PMA-treated cells or unstimulated cells $(0)$ is shown. 
and 2 with lanes 5 and 6 ). Together, these results demonstrate that, although not necessary for Tat transactivation, the TRE/ CRE-like DSE motifs are required for c-Fos transactivation of the HIV-1 LTR in colon epithelial cells. However, whether one or both of the motifs is required is not known, as each site was not mutated individually.

Differential c-Fos transactivation in three colon epithelial cell lines. To assess whether the marked increase in CAT activity stimulated by c-Fos and PMA or TNF $\alpha$ treatment was specific for the $\mathrm{CD}^{+}{ }^{+} \mathrm{SW} 620$ cell line or reflected a more general phenomenon, we conducted parallel transfection experiments with two additional human colon epithelial cell lines previously characterized in our laboratory, HT29 and T84 (18). The HT29 cells used in these studies do not express the CD4 cell surface glycoprotein but are, nevertheless, infectible by HIV-1 via a non-CD4-mediated pathway involving galactosyl ceramide or a closely related molecule $(18,46)$. As shown in Fig. 4, there was strong transcriptional activation of the -91 / +232 LTR CAT template when HT29 cells were cotransfected with the c-Fos expression plasmid and stimulated with PMA or TNF $\alpha$. T84 cells, a well-differentiated colonic epithelial line of crypt origin, also lack CD4 but are not infectible by HIV-1 and do not activate HIV-1 LTR transcription in response to TNF $\alpha$ or PMA stimulation (18). T84 cells cotransfected with the $-91 /+232$ LTR CAT template and a c-Fos expression vector and stimulated with PMA or TNF $\alpha$ produced only a modest increase in CAT activity (Fig. 4). The markedly lower activation response in cotransfected T84 cells compared with the HIV-1-infectible cell lines SW620 and HT29 suggests that activation of the HIV-1 LTR in colon epithelial cells is limited to

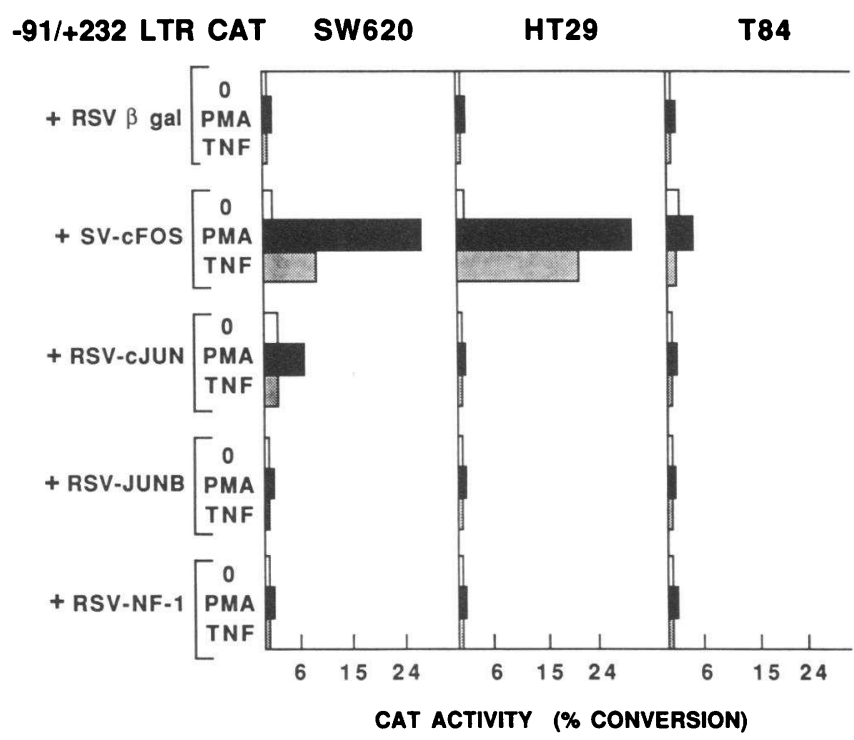

Figure 4. Effects of various expression plasmids on HIV-1 LTR-mediated gene transcription in three colon epithelial cell lines. SW620 (left), HT29 (center), and T84 (right) colon epithelial cells were cotransfected with $5 \mu \mathrm{g}$ of the $-91 /+232$ CAT reporter plasmid together with $5 \mu \mathrm{g}$ of the expression vectors indicated. Cells either received no treatment (open bars), or were stimulated with PMA (solid bars) or TNF $\alpha$ (stippled bars) as indicated in Fig. 1. Length of the bars represents CAT activity expressed as percent conversion as calculated in the legend of Fig. 1. These data are from a single representative experiment. Similar results were obtained in two to three repeated experiments.

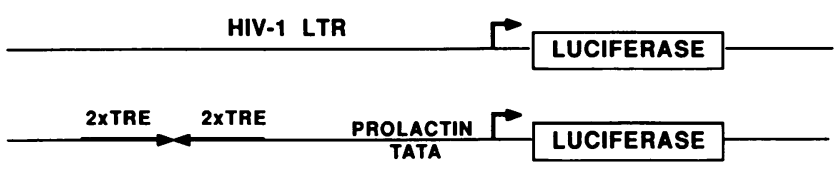

B

\begin{tabular}{|c|c|c|c|c|}
\hline & \multicolumn{2}{|c|}{ SW620 } & \multicolumn{2}{|r|}{ I84 } \\
\hline IRE/AP1 LUC & RLU & fold increase) & RLU & old increase \\
\hline -PMA & 315 & & 4959 & \\
\hline +PMA & 1512 & (4.8X) & 29228 & (5.9X) \\
\hline$V-1$ LTR LUC & & & & \\
\hline -PMA & 4236 & & 148136 & \\
\hline +PMA & 51295 & $(12 X)$ & 146392 & (1X) \\
\hline
\end{tabular}

Figure 5. Phorbol ester-stimulated transactivation response in T84 and SW620 cells transfected with a TRE/AP1-LUC or HIV-1 LTRLUC reporter gene plasmid. $(A)$ Structure of the luciferase reporter plasmids. HIV-1 LTR-LUC contained LTR sequences upstream of +80. TRE/API-LUC contained four consensus TRE motifs upstream of a rat prolactin minimal promoter. $(B)$ Expression results of SW620 (left) and T84 ( right) transfected with a TRE/AP1-LUC or an HIV-1 LTR-LUC reporter gene plasmid as described in Methods and treated with PMA $(20 \mathrm{ng} / \mathrm{ml})$ or no PMA. Data are the mean of three transfection experiments and are expressed as relative light units per $10 \mathrm{~s}$ using equivalent amounts of protein from cell extracts. The fold increase in response to PMA stimulation is indicated in parentheses. The greater luciferase activity observed in T84 cells reflects their higher transfection efficiency.

colonic cell types capable of mediating PMA or TNF $\alpha$-stimulated activation signals to the HIV-1 LTR.

In contrast to the c-Fos expression plasmid, little or no increase in CAT reporter gene activity was noted after PMA or TNF $\alpha$ stimulation in any of the colon epithelial cell lines cotransfected with c-Jun, junB, or NF1 expression plasmids or with the control RSV- $\beta$ gal expression vector. However, RSV-cjun, RSV-junB and SV-c-fos plasmids were functional in the three human cell lines, since in controls they readily transactivated a reporter gene containing multiple consensus TRE motifs (data not shown).

T84 cells can mediate a PMA transactivation response to a TRE-dependent reporter gene but not to the HIV-1 LTR. To determine whether the inability of T84 cells to mediate PMA activation signals to the HIV-1 LTR was promoter specific or represented a more general defect in a signal transduction pathway, we tested the ability of another reporter gene construction, TRE/AP1-LUC, to be activated by PMA in T84 cells. This construction (Fig. $5 \mathrm{~A}$ ) contains multiple consensus TRE motifs upstream of a rat prolactin minimal promoter (42) linked to the firefly luciferase gene and is transcriptionally responsive to PMA in SW620 cells (Fig. 5 B). Similarly, in T84 cells transfected with the TRE/AP1-LUC reporter gene, a nearly sixfold stimulation of luciferase activity was noted in response to PMA stimulation (Fig. $5 \mathrm{~B}$ ). These data indicate that T84 cells, like SW620 cells, are capable of mediating PKC activation signals to trigger gene activation, presumably by activating TRE-binding Jun/Fos transcription factors.

In contrast to the TRE/AP1-LUC plasmid, when an HIV-1 LTR-LUC reporter gene construct (Fig. $5 A$ ) containing com- 
plete LTR sequences upstream of +80 but lacking a fully transcribed noncoding $5^{\prime}$ leader sequence was transfected into SW620 or T84 cells, a strong PMA response was detected in SW620 cells, but not in T84 cells under identical conditions (Fig. 5 B). PMA-treated T84 cells were also unable to activate a full-length LTR CAT construct that included downstream LTR sequences to nucleotide position +232 or a full-length proviral clone (data not shown). These data are consistent with our previous results, indicating that T84 cells are unable to mediate PMA activation of the HIV-1 LTR (18). Although T84 cells can transmit PMA activation signals to AP-1-dependent reporter genes, they are apparently deficient in the intracellular signaling that is required to trigger the activation of the HIV-1 LTR by PMA.

Downstream sequence motifs weakly bind recombinant $c$ Jun protein. Having documented the importance of the DSE motifs in c-Fos transactivation of the HIV-1 LTR, we next assessed their AP-1 binding properties. Because c-Fos itself does not bind DNA, we performed gel mobility shift experiments with purified recombinant trpE-c-Jun fusion protein, which, as a major component of AP-1 complexes, was previously shown to bind with high affinity to a classical TRE motif (26). When increasing amounts of trpE-c-Jun were incubated with an HIV-1 LTR restriction fragment $(+80 /+222)$ containing the DSE motifs, a specific gel shift complex was formed (Fig. $6 \mathrm{~A}$, lane 5). This c-Jun-DNA complex migrated near a TRE deoxyoligonucleotide c-Jun binding complex, but displayed less binding activity (compare Fig. $6 \mathrm{~A}$, lanes 1 and 5). To assess whether c-Jun could bind to the HIV-1 DSE sites, we synthesized a series of short double-stranded deoxyoligonucleotides containing the TRE/CRE-like motifs (Table I). In the gel mobility shift assays shown in Fig. $6 \mathrm{~B}$, an oligonucleotide containing the +160 DSE-2 motif formed specific complexes with trpE-c-Jun (Fig. $6 B$, lanes 2 and 3 ) that comigrated with complexes formed on the collagenase TRE oligonucleotide control (Fig. $6 \mathrm{~B}$, lane 1 ), albeit with less binding activity. In contrast, an oligonucleotide with a mutation in the +160 motif $(+160 \mathrm{~m})$ formed no detectable trpE-c-Jun complexes (Fig. $6 \mathrm{~B}$, lanes 4 and 5). The +95 DSE-1 oligonucleotide formed only weakly detectable complexes with trpE-c-Jun (Fig. $6 \mathrm{~B}$, lanes 6 and 7). These results indicate that, although c-Jun can recognize and bind the downstream +160 and +95 DSE motifs, it does so less efficiently than to a classical TRE oligonucleotide.

To more accurately assess the relative binding affinities of the various oligonucleotides for c-Jun, increasing amounts of unlabeled $+160,+160 \mathrm{~m}$ and +95 DSE oligonucleotides were competed for trpE-c-Jun binding with the labeled collagenase TRE oligonucleotide (Fig. $6 C$ ). In accordance with their apparent binding efficiencies documented in Fig. $6 \mathrm{~B}$, the +160 DSE-2 oligonucleotide competed with the TRE oligonucleotide for c-Jun binding (Fig. $6 C$, lanes 5 and 6 ) better than the +95 DSE-1 oligonucleotide (lanes 9 and 10 ), or the $+160 \mathrm{~m}$ DSE-2 oligonucleotide (lanes 7 and 8 ). However, the homologous collagenase TRE oligonucleotide was a substantially better competitor than any of the HIV-1 LTR derived oligonucleotides (Fig. $6 C$, lanes 1-3).

$T 84$ cell nuclear extracts produce a distinct gel shift pattern of CRE motif binding activity. To identify the DNA binding activities present in colon epithelial cells that recognize HIV-1 LTR sequence motifs, we prepared cell-free nuclear extracts (44) from T84, SW620, and HT29 cells, incubated them with labeled oligonucleotide sequence motifs, and resolved DNA binding complexes by gel electrophoresis (Fig. 7). Fig. $7 A$ shows that specific gel shift complexes form with oligonucleotides containing Sp1 (lanes 1-3) and NF1 binding sites (lanes 4-6). Sp1 and NF1 are common transcription factors present in a wide variety of cell types and their binding sites are found in many cellular and viral promoters, including HIV-1 $(4,39)$; their similar DNA-binding activities among the three cell lines provide, therefore, an indication of the quality of the colonic cell nuclear extracts.

Because the downstream motifs in the HIV-1 LTR closely resemble consensus TRE and CRE motifs, we tested each cell extract for DNA binding activity to oligonucleotides with a classical TRE $(20,21)$ or CRE (30) motif (Table I). Although classical TRE and CRE motifs are nearly identical in primary sequence, the collagenase TRE motif is a strong binding site for members of the Jun/Fos family, whereas the somatostatin CRE motif is a preferential binding site for CREB/ATF family members $(20,21,30)$. The gel shift data shown in Fig. $7 B$ indicate that each of the three colon epithelial cell lines contain separate CRE (lanes 1-3) and TRE (lanes 4-6) binding activities that do not cross compete (lanes 2 and 6 ). Although the individual CRE and TRE complexes each exhibit a similar gel migration pattern with all three cell nuclear extracts, the relative DNA binding activity of one of the two major complexes formed with the CRE oligonucleotide was different with the nuclear extract of T84 compared with SW620 and HT29 cells. The faster-migrating CRE complex with T84 cell nuclear extract was markedly reduced compared with the slower-migrating CRE complex and compared with the CRE complexes formed with identical amounts of SW620 and HT29 cell nuclear extract (Fig. $7 \mathrm{~B}$, lanes $1-3$ ). Together, these data indicate that the DNA binding activities in colon epithelial cells are very similar; the one notable exception being the CRE binding activity in T84 cells, which appears to be deficient in the faster-migrating CRE gel shift complex.

Downstream sequence elements form novel c-fos-containing complexes with colonic epithelial cell proteins. To further assess the DNA binding activity of the TRE/CRE-like motifs in the HIV-1 LTR, we performed gel mobility shift experiments including oligonucleotides containing the +160 and +95 DSE motifs (Table I). The results in Fig. 8 show that a specific DNA binding activity can be detected with the +160 and +95 DSE oligonucleotides in nuclear extracts from each of the colon epithelial cell lines (Fig. $8 A$, lanes 1 and 5). The DNA binding activity detected with the T84 cell nuclear extract was, however, weak compared with the relative binding activity generated by identical amounts of SW620 or HT29 cell nuclear extracts. When unlabeled oligonucleotides were used to compete for complex formation, the unlabeled collagenase TRE oligonucleotide did not interfere with the formation of either the +95 or +160 DSE gel shift complexes (Fig. $8 \mathrm{~A}$, lanes 2 and 6 ). In contrast, the somatostatin CRE oligonucleotide blocked the formation of these gel shift complexes (Fig. $8 \mathrm{~A}$, lanes 3 and 7) to a degree similar to or better than that of homologous competition with the +160 or +95 oligonucleotide (lanes 4 and 8 ). These results indicate that the DNA binding proteins in colonic epithelial cells that recognize the HIV-1 LTR DSE also recognize a classical CRE motif.

Using the SW620 nuclear extract, the gel shift complex formed on the +160 DSE- 2 oligonucleotide clearly migrates faster in the gel than the complex formed on the collagenase 
A

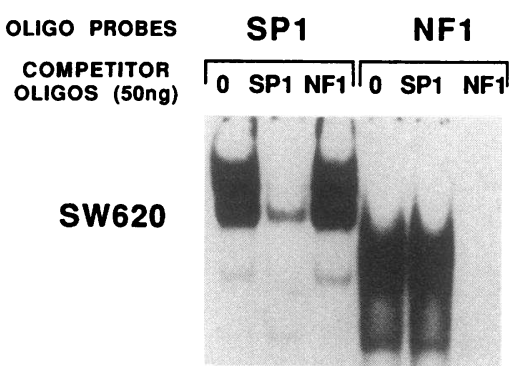

HT29

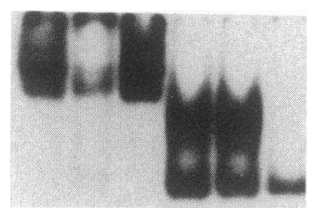

T84

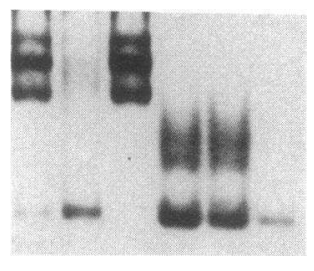

$\begin{array}{llllll}1 & 2 & 3 & 4 & 5 & 6\end{array}$

B
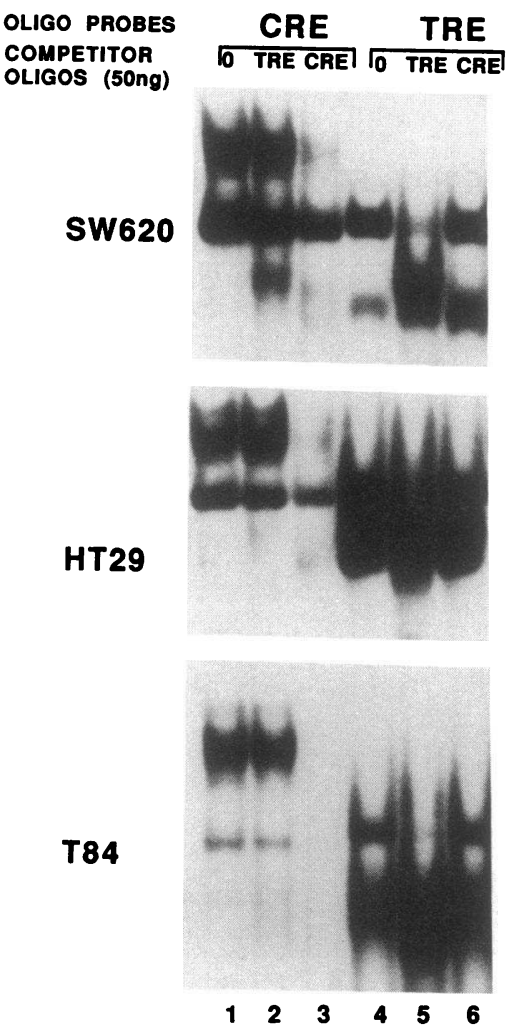

Figure 7. Comparative binding activities of colon epithelial cell nuclear extracts to DNA sequence motifs. A constant amount of nuclear extract from SW620 (top), HT29 (middle), and T84 (bottom) colon epithelial cell lines were incubated with the ${ }^{32} \mathrm{P}$. end-labeled oligonucleotide probes $(\sim 0.5 \mathrm{ng})$ as indicated. ProteinDNA complexes were resolved by gel electrophoresis. $(A)$ Gel shift complexes formed with Sp1 (lanes 1-3) and NF1 oligonucleotides (lanes 4-6) in the absence (lane 1) or presence of unlabeled $\mathrm{Sp} 1$ (lanes 2 and 5) or NF1 competitor oligonucleotide (lanes 3 and 6 ).

(B) Gel shift complexes formed with CRE (lanes 1-3) and TRE oligonucleotides (lanes 4-6) in the absence (lane 1) or presence of unlabeled TRE (lanes 2 and 5) or CRE competitor oligonucleotide (lanes 3 and 6). Migration of the unbound free probe is not shown. Competition, for unknown reasons, sometimes increased the formation of nonspecific complexes (lanes 2, 3, 5 , and 6 ).

the somatostatin CRE motif reduced formation of the +160 DSE gel shift complex (Fig. $8 B$, lane 4) again to an extent similar to that seen with the homologous oligonucleotide (lane
6). Identical results were obtained with the +95 DSE-1 oligonucleotide (data not shown).

To determine whether c-Fos was a component of the CRElike DSE gel shift complex, a c-Fos antibody (18C3) that was previously shown to specifically interfere with c-Fos-containing complexes (47) was included in the binding reactions before adding DNA probe (Fig. $8 \mathrm{C}$ ). Since the c-Fos gene is induced by serum, for these gel shift experiments SW620 serum-starved extracts were used to assess whether the DSE complex would be affected. As shown in Fig. $8 C$, the c-Fos antibody blocked the formation of the CRE-like DSE complex (lane 2, complex I). Interestingly, using serum-starved extracts, a new complex was also formed that migrated slower in the gel than the CRE-like DSE complex (Fig. $8 C$, lane 1, complex II). This new complex was also somewhat diminished by the anti-c-Fos antibody (lane 2, complex II). c-Fos antibody was specific for the comigrating complex shared by the DSE and the CRE, as shown in Fig. $8 C$, lanes 3 and 4, since it was able to block only the faster migrating CRE complex (lane 4). Thus, although the HIV-1 DSE motifs can form more than one gel shift complex, the faster-migrating complex appears to be a c-Fos-containing CRE-like binding complex.

\section{Discussion}

We describe DSE in the transcribed noncoding 5 ' leader sequences of the HIV-1 LTR that are c-Fos responsive and are differentially activated in three human colon carcinoma epithelial cell lines. One or both of the DSE, shown in relation to the HIV-1 LTR in Fig. $1 A$ and at the nucleotide level in Fig. $3 A$, mediate c-Fos transactivation of the HIV-1 LTR in colonic epithelial cells stimulated with PMA or TNF $\alpha$. These are the most downstream cis-regulatory elements described thus far in the HIV-1 LTR. These findings suggest that previously unrecognized sequence elements that reside downstream of TAR in the transcribed noncoding 5 ' leader sequence may contribute to the activation and regulation of HIV-1 gene expression.

Role of the c-Fos-responsive DSE sites in the activation of the HIV-1 LTR. The first downstream element, DSE-1, is located immediately downstream of TAR at nucleotide position +95 and appears to be composed of two partially overlapping TRE/CRE-like sites. DSE-2, the other HIV-1 c-Fos-responsive element, is located at position +160 and has perfect sequence identity to the functional AP-1 binding sites found in the 72-bp repeats of SV40 and the enhancer region of polyoma virus (TTAGTCAG) (48). The DSE-2 site is also identical to two of the three PMA-responsive elements recently identified in the HIV-1 pol gene, which are thought to comprise a potential HIV-1 intragenic enhancer element (49). Although the in vivo role of the DSE elements remains to be demonstrated, it is noteworthy that Jun/Fos expression plasmids can stimulate new viral production from a transfected HIV-1 proviral plasmid clone in a highly transfectible human colonic epithelial cell line (Roebuck, K. A., unpublished results).

The c-Fos-responsive DSE sites may comprise a downstream LTR enhancer that functions independently of, or in concert with, the upstream NF $\kappa$ B-binding enhancer to activate HIV-1 transcription. An additional inducible enhancer element in the viral LTR may provide a mechanism to broaden the viral response to extracellular stimuli and activate transcription under a wider variety of cellular conditions. Indeed, functional redundancy is a common feature of viral as well as 


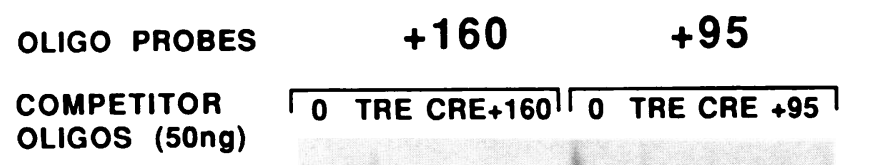

SW620

HT29

184

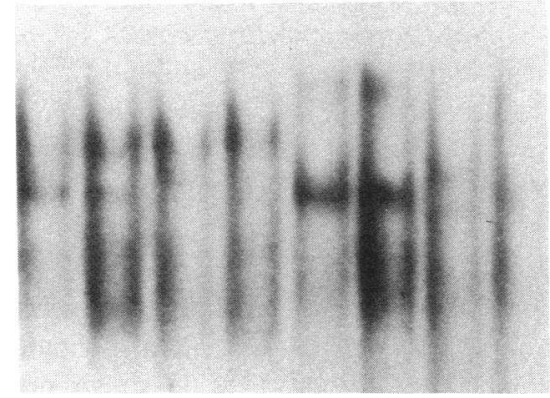

1

C

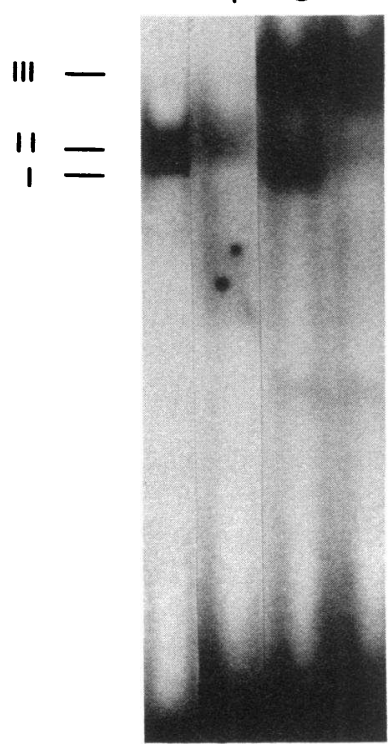

\section{OLIGO PROBES \\ COMPETITOR OLIGOS (50ng)}

\section{TRE +160 CRE

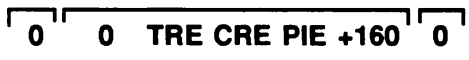

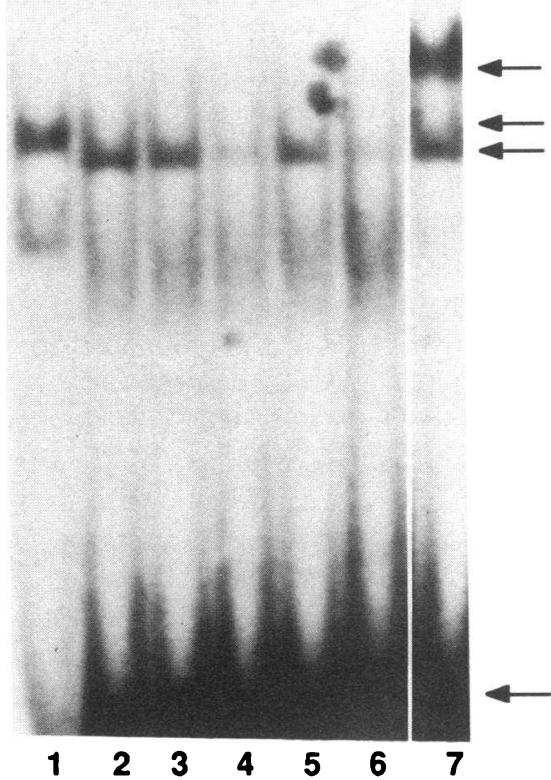

Figure 8. Characterization of novel TRE/CRE-like motif binding activities in colon epithelial cell nuclear extracts. ${ }^{32} \mathrm{P}$-end-labeled HIV-1 DSE-1 and -2 oligonucleotides shown in Table $\mathrm{I}(\sim 0.5 \mathrm{ng})$ were assayed for binding activity as described in Methods and the legend of Fig. 7. (A) Gel shift complexes formed with +160 (lanes 1-4) and +95 DSE motif oligonucleotides (lanes 5-8) with SW620 (top), HT29 (middle), and T84 (bottom) colon epithelial cell extracts. The +160 and +95 gel shift complexes were not competed (lanes 1 and 5 ) or competed with $50 \mathrm{ng}$ of unlabeled oligonucleotide as indicated above each lane. Migration of the unbound free probe is not shown. (B) Comparison of CRE (lane 7), TRE (lane 1), and HIV-1 DSE oligonucleotide complexes (lanes 2-6) formed with SW620 cell nuclear extracts. The +160 DSE-2 complex was either noncompeted or competed with $50 \mathrm{ng}$ of the unlabeled oligonucleotides shown in Table I as indicated above each lane. Three major distinguishable complexes are indicated to the right by arrows. Migration of the unbound free probe is indicated at the bottom right by an arrow. Note that the +160 DSE-2 gel shift complex migrates differently than the TRE complex (lane 1) and comigrates with the faster-migrating CRE complex (lane 7). (C) Comparison of the gel shift complexes formed on the +160 DSE-2 (lane 1 ) and CRE (lane 3 ) with serum-starved SW620 nuclear extract. Binding reactions were done in the absence (lanes 1 and 3 ) or in the presence of a c-fos monoclonal antibody (lanes 2 and 4 ) as indicated above each lane. c-fos antibody blocks the formation of the CRE-like DSE complex (lane 2, complex I) and the faster-migrating CRE complex (lane 4, complex $I$ ). Note that extracts from serum-starved cells also have a slower migrating complex (complex $I I$ ) on the DSE motif, which also is partially blocked by c-fos antibody. 
cellular regulatory regions and is a potential mechanism to increase the viral cell host range. A functional enhancer downstream of the viral transcription initiation site is also consistent with reports indicating the upstream NF $\kappa$ B-binding enhancer was not essential for HIV-1 infectivity (50). In particular, enhancer-bound $\mathrm{NF}_{\boldsymbol{K}} \mathrm{B}$ in vitro (51) or nuclear-translocated NF $k B$ in vivo (52) was not sufficient to activate HIV-1 gene transcription. Recently, DNA sequences within the transcribed noncoding leader of HIV-1 and HIV-2 have been reported to play a positive and negative role, respectively, in basal gene expression $(53,54)$. We note that the DSE sequences are transcribed into RNA as is the Tat-responsive element. However, c-Fos, unlike Tat, acts through DNA elements in association with other leucine zipper proteins. Nonetheless, we have not formally ruled out the possibility that c-Fos may bind to RNA and activate LTR transcription, perhaps in a manner similar to the Tat and TAR interaction.

A functional TRE/CRE-like sequence motif in the HIV-1 LTR implies that members of the Jun/Fos and/or CREB/ ATF families of transcriptional activators play a role in the regulation of HIV-1 gene expression. These transcription factors are highly regulated. Their genes are differentially expressed $(29,55,56)$ and their products have different biological properties $(25,38,57)$, which can confer negative as well as positive transcriptional control of target genes $(19,22,38,58$, 59). Recently, Jun/Fos and/or CREB/ATF have been implicated in the transcription of other retroviruses, including HTLV-1 (60), human foamy virus (61), bovine leukemia virus-1 (62), and feline immunodeficiency virus-1 (63). In addition, previously recognized HIV-1 LTR transactivator proteins encoded by other viruses can activate gene expression through functional TRE and CRE motifs (e.g., the product of the Epstein-Barr early immediate gene BZLF1 [64], which encodes a leucine zipper factor similar to $\mathrm{C}-\mathrm{Fos}$, and the $\mathrm{X}$ protein of hepatitis B virus [41], which can form complexes with ATF proteins [65]).

Intracellular signaling pathways that activate the c-Fos-responsive DSE sites appear to differ among human colonic epithelial cells. As an immediate early gene, c-Fos plays a crucial role in the intracellular transduction of extracellular stimuli; its activation, along with c-jun, is important for entry into the cell cycle (23). Our results suggest that c-Fos induction might be an important trigger in the activation of HIV-1 gene expression. A transfected c-Fos expression vector stimulated HIV-1 LTR-dependent gene transcription in concert with activators of PKC in HIV-1-infectible colon epithelial cell lines, but not in the noninfectible colon epithelial cell line T84. However, T84 cells did mediate PMA-activated intracellular signals to a reporter gene construction containing multiple TRE motifs. Thus, it appears that the c-Fos-responsive DSE motifs are activated in HIV-1-infectible colon epithelial cells by a cellular signaling pathway different from that activating classical Jun/Fos-binding TRE elements. Activation of PKC may induce cell typespecific posttranslational modifications of c-Fos directly or it may differentially regulate a dimerization partner of c-Fos, such as a member of the CREB/ATF family $(55,66,67)$. Alternatively, it is possible that PKC could differentially influence other regulatory proteins in the three cell lines, for example, those involved in the modulation of c-Fos and/or CREB/ ATF binding activities, including IP-1, an inhibitor protein of Fos/Jun that is regulated by extracellular signals (68) or CREM and Ref-1, which modulate CREB and AP-1 binding activities, respectively $(66,69)$.
HIV-1 DSE motifs appear to differ from classical TRE motifs. Although the DSE motifs in the HIV-1 LTR have a high degree of sequence similarity to classical TRE motifs and functional AP-1 binding sites, our data suggest that these motifs, perhaps because of their context, do not function as typical AP-1 binding TRE sites. First, recombinant c-Jun bound the HIV-1 DSE sites quite poorly compared with the collagenase TRE motif. Second, nuclear protein complexes formed on the HIV-1 DSE motifs migrated in gels differently from the TRE motif complex and were not blocked by competition with the TRE sequence oligonucleotide. Third, in transient transfection experiments, c-Jun did not synergize with c-Fos to activate HIV-1 LTR transcription, but rather attenuated the c-Fos transactivation response. Finally, T84 colon epithelial cells could not mediate PMA or TNF $\alpha$ activation signals to the HIV-1 DSE motifs to produce efficient c-Fos transactivation of the HIV-1 LTR, but could readily mediate PMA activation signals to the collagenase TRE motif to transactivate AP-1-dependent reporter gene expression. Collectively, these data indicate that DSE-1 and DSE-2 are probably interacting with transcription factors consisting of components other than, or in addition to, those of the AP-1/Jun/Fos family to mediate HIV-1 gene expression.

Differential c-Fos transactivation of SW620, HT29, and T84 cells correlates with a novel CRE-like binding activity in colon epithelial cells. The ability of c-Fos to transactivate expression of the HIV-1 LTR in human colon epithelial cells correlated with a CRE-like binding activity. In the T84 cell extracts, one of the CRE complexes was weakly detected compared with its counterpart in the HT29 and SW620 cell extracts. This latter CRE complex comigrated with those formed on the DSE motifs. In addition, the comigrating CRE and DSE complexes were blocked when incubated with an anti-c-Fos monoclonal antibody ( $18 \mathrm{C} 3$ ), shown previously to specifically interfere with c-Fos-containing gel shift complexes (47). The second CRE complex, which does not comigrate with the DSE complex, was unaffected by the antibody. Thus, c-Fos is a component of both the CRE and DSE complexes. This is consistent with studies demonstrating that, as a heterodimer, c-Fos binds to $\mathrm{CRE}$ as well as TRE $(25,33)$. It also suggests that the c-Fos transactivation of the HIV-1 LTR is most likely due to a direct interaction of c-Fos with the DSE motifs.

Although cotransfections with the c-Fos expression plasmid resulted in high levels of transcriptional activity from a construction containing the HIV-1 DSE motifs, different combinations of other members of the Jun/Fos family failed to stimulate comparable levels of HIV-1 LTR expression in PMA- or TNF $\alpha$-stimulated colon epithelial cells. Because Jun forms a more stable complex as a heterodimer with Fos than as a Jun-Jun homodimer, in many cell systems c-Jun cotransfected with c-Fos stimulates higher levels of gene expression than c-jun alone $(19,25,27)$. However, in the colonic epithelial cells, cotransfected c-Jun reduced expression of the HIV-1 LTR stimulated by c-Fos transactivation. Because c-Fos requires a partner to bind DNA as a heterodimer (19), it is conceivable in our studies that c-Jun displaced, by a direct competition or squelching mechanism, the protein dimerization partner that combines with c-Fos to form the HIV-1 DSE activation complex. This putative dimerization partner of $\mathrm{c}$-Fos might be a member of the CREB/ATF family that cross-combines with c-Fos to form a hybrid dimer with an altered sequence binding specificity in which CRE-like, rather than TRE-like, sequences are preferred (32-34). This possibility is 
consistent with our DNA binding studies demonstrating selective competition of the DSE motifs with classical CRE motifs. However, we note that two members of the CREB/ATF family tested in our system, CREB and ATF-2, likewise attenuated c-Fos transactivation, indicating that c-Fos may dimerize with other yet unknown transcription factors to activate the HIV-1 LTR (Roebuck, K. A., unpublished data). In MHC class II gene promoters, c-Fos has been shown to dimerize with an unknown protein factor in binding to the nonconsensus TRE $\mathrm{X} 2$ box (70). It is also possible that $\mathrm{c}-$ Fos interacts with nonAP-1/CREB/ATF proteins, such as those from the C/EBP and NF-IL6 basic-leucine zipper family (71).

\section{Acknowledgments}

We thank C. Lu, S. Lundgren, M. Arce, S. Kim, G. Martinez, J. Han, and T. Mchezaji for technical assistance; T. Smeal for providing the trpE-c-Jun protein; K. A. Jones, A. Siddiqui, M. G. Rosenfeld, A. B. Rabson, M. C. Nehls, and M. Karin for providing plasmids; and R. A. Rippe for the PIE oligonucleotide. We also thank E. Morzycka-Wroblewska for critical reading of the manuscript before submission.

This research was supported by National Institutes of Health grant DK-40582, a grant from the University of California Universitywide AIDS Research Program (UARP), and a Fellowship to K. A. Roebuck from the UARP.

\section{References}

1. Greene, W. C. 1991. The molecular biology of human immunodeficiency virus type 1 infection. N. Engl. J. Med. 324:308-317.

2. Vaishnav, Y. N., and F. Wong-Staal. 1991. The biochemistry of AIDS. Annu. Rev. Biochem. 60:557-630.

3. Varmus, H. 1988. Regulation of HIV-1 and HTLV gene expression. Genes Dev. 2:1055-1062.

4. Gaynor, R. B. 1992. Cellular transcription factors involved in the regulation of HIV-1 gene expression. AIDS (Phila.). 6:347-363.

5. Nabel, G., and D. Baltimore. 1987. An inducible transcription factor activates expression of human immunodeficiency virus in T-cells. Nature (Lond.). 326:711-713.

6. Jones, K. A., P. A. Luciw, and N. Duchange. 1988. Structural arrangement of transcription control domains within the 5'-untranslated leader regions of the HIV-1 and HIV-2 promoters. Genes Dev. 2:1101-1111.

7. Price, R. W., B. Brew, J. Sidtis, M. Rosenblum, A. C. Scheck, and P. Cleary. 1988. The brain in AIDS: central nervous system HIV-1 infection and AIDS dementia complex. Science (Wash. DC). 239:586-592.

8. Rogers, V. D., and M. F. Kagnoff. 1988. Acquired immunodeficiency syndrome and disease of the gastrointestinal tract. Immunol. Allergy Clin. N. Am. 8:451-467.

9. Nelson, J. A., C. A. Wiley, C. Reynolds-Kohler, C. E. Reese, W. Margaretten, and J. A. Levy. 1988. Human immunodeficiency virus detected in bowel epithelium from patients with gastrointestinal symptoms. Lancet. i:259-262.

10. Levy, J. A., W. Margaretten, and J. Nelson. 1989. Detection of HIV in enterochromaffin cells in the rectal mucosa of an AIDS patient. Am. J. Gastroenterol. 84:787-789.

11. Fox, C. H., D. Kotler, A. Tierney, C. S. Wilson, and A. S. Fauci. 1989. Detection of HIV in RNA in the lamina propria of patients with AIDS and gastrointestinal disease. J. Infect. Dis. 159:467-471.

12. Moyer, M. P., R. I. Huot, A. Ramirez, Jr., S. Joe, M. S. Meltzer, and H. E. Gendelman. 1990. Infection of human gastrointestinal cells by HIV-1. AIDS Res. Hum. Retroviruses. 6:1409-1415.

13. Heise, C., S. Dandekar, P. Kumar, R. Duplanteir, R. M. Donovan, and C. H. Halsted. 1991. Human immunodeficiency virus infection of enterocytes and mononuclear cells in human jejunal mucosa. Gastroenterology. 100:15211527.

14. Amerongen, H. M., R. Welzin, C. M. Farnet, P. Michetti, W. A. Haseltine, and M. R. Neutra. 1991. Transepithelial transport of HIV-1 by intestinal M cells: a mechanism for transmission of AIDS. J. Acquired Immune Defic. Syndr.
4:760-765.

15. Fantini, J., N. Yahi, S. Baghdiguian, and J.-C. Chermann. 1992. Human colon epithelial cells productively infected with human immunodeficiency virus show impaired differentiation and altered secretion. J. Virol. 66:580-585.

16. Phillips, D. M., and A. S. Bourinbaiar. 1992. Mechanisms of HIV spread from lymphocytes to epithelia. Virology. 186:261-273.

17. Gill, J. M., L. R. Sutherland, D. L. Church, and the University of Calgary
Gastrointestinal/HIV study group. 1992. Gastrointestinal tissue cultures for HIV in HIV-infected/AIDS patients. AIDS (Phila.). 6:553-556.

18. Omary, M. B., D. A. Brenner, L. Y. deGrandpre, K. A. Roebuck, D. D. Richman, and M. F. Kagnoff. 1991. Human immunodeficiency virus-1 infection and expression in human colonic cells: infection and expression in CD4 positive and CD4 negative cell lines. AIDS (Phila.). 5:275-281.

19. Karin, M. 1991. The AP1 complex and its role in transcriptional control by protein kinase C. In The Hormonal Control Regulation of Gene Transcription. P. Cohen and J. G. Foulkes, editors. Elsevier Science, Amsterdam, The Netherlands. 235-253.

20. Angel, P., M. Imagawa, R. Chiu, B. Stein, R. J. Imbra, H. J. Rahmsdorf, C. Jonat, P. Herrlich, and M. Karin. 1987. Phorbol ester-inducible genes contain common cis element recognized by a TPA-modulated trans-acting factor. Cell. 49:729-739.

21. Brenner, D. A., M. O’Hare, P. Angel, M. Chojkier, and M. Karin. 1989. Prolonged activation of Jun and collagenase genes by TNF $\alpha$. Nature (Lond.) 337:661-663.

22. Castellazzi, M., G. Spyrou, N. La Vista, J.-P. Dangy, F. Piu, M. Yaniv, and G. Brun. 1991. Overexpression of c-jun, junB, or junD affects cell growth differently. Proc. Natl. Acad. Sci. USA. 88:8890-8894.

23. Kovary, K., and R. Bravo. 1991. The jun and fos protein families are both required for cell cycle progression in fibroblasts. Mol. Cell. Biol. 9:4466-4472.

24. Franza, B. R., F. J. Rauscher, S. F. Josephs, and T. Curran. 1988. The fos complex and fos related antigens recognize sequence elements that contain API binding sites. Science (Wash. DC). 239:1150-1153.

25. Ryseck, R. P., and R. Bravo. 1991. c-jun, JunB, and JunD differ in their binding affinities to AP-1 and CRE consensus sequences: effects of Fos proteins. Oncogene. 6:533-542.

26. Smeal, T., P. Angel, J. Meek, and M. Karin. 1989. Different requirements for the formation of Jun:Jun and Jun:Fos complexes. Genes Dev. 3:2091-2100.

27. Zerial, M., L. Toschi, R. P. Ryseck, M. Schuermann, R. Muller, and R. Bravo. 1989. The product of a novel growth factor activated gene, fosB, interacts with JUN proteins enhancing their DNA binding activity. EMBO (Eur. Mol. Biol. Organ.) J. 8:805-813.

28. Spandidos, D. A., M. Yiagnisis, and A. Pintzas. 1989. Human immunodeficiency virus long terminal repeat responds to transformation by the mutant $\mathrm{T} 24$ $\mathrm{H}$-rasl oncogene and it contains multiple AP-1 binding TPA-inducible consensus sequence elements. Anticancer Res. 9:383-386.

29. Flint, K. J., and N. C. Jones. 1991. Differential regulation of three members of the ATF/CREB family of DNA-binding proteins. Oncogene. 6:2019-2026

30. Montminy, M. R., K. A. Sevarino, J. A. Wagner, G. Mandel, and R. H. Goodman. 1986. Identification of a cyclic-AMP-responsive element within the rat somatostatin gene. Proc. Natl. Acad. Sci. USA. 83:6682-6686.

31. Sakurai, A., T. Maekawa, T. Sudo, S. Ishii, and A. Kishimoto. 1991. Phosphorylation of cAMP response element-binding protein, CRE-BP1, by cAMP-dependent protein kinase and protein kinase C. Biochem. Biophys. Res. Commun. 181:629-635

32. Benbrook, D. M., and N. C. Jones. 1990. Heterodimer formation between CREB and JUN proteins. Oncogene. 5:295-302.

33. Hai, T., and T. Curran. 1991. Cross-family dimerization of transcription factors Fos/Jun and ATF/CREB alters DNA binding specificity. Proc. Natl. Acad. Sci. USA. 88:3720-3724.

34. Ivashkiv, L. B., H.-C. Liou, C. J. Kara, W. W. Lamph, I. Verma, and L. H. Glimcher. 1990. mXBP/CRE-BP2 and c-jun form a complex which binds to the cyclic AMP, but not to the 12-O-Tetradecanoylphorbol-13-Acetate, response element. Mol. Cell. Biol. 10:1609-1621.

35. Macgregor, P. F., C. Abate, and T. Curran. 1990. Direct cloning of leucine zipper proteins: Jun binds cooperatively to the CRE with CRE-BP1. Oncogene. 5:451-458.

36. Hoeffler, J. P., J. W. Lustbader, and C. Y. Chen. 1991. Identification of multiple nuclear factors that interact with cyclic adenosine $3^{\prime}, 5^{\prime}$-monophosphate response element-binding protein and activating transcription factor- 2 by protein-protein interactions. Mol. Endocrinol. 5:256-266.

37. Dinter, H., R. Chiu, M. Imagawa, M. Karin, and K. A. Jones. 1987. In vitro activation of the HIV-1 enhancer in extracts from cells treated with phorbol ester tumor promoter. EMBO (Eur. Mol. Biol. Organ.) J. 6:4067-4071.

38. Chiu, R., P. Angel, and M. Karin. 1989. jun-B differs in its biological properties from and is a negative regulator of c-jun. Cell. 59:979-986.

39. Nehls, M. C., R. A. Rippe, L. Veloz, and D. A. Brenner. 1991. Transcriptional factors nuclear factor 1 and Spl interact with the murine collagen al (I) promoter. Mol. Cell. Biol. 11:4065-4073.

40. Ross, E. K., A. J. Buckler-White, A. B. Rabson, G. Englund, and M. A. Martin. 1991. Contribution of $\mathrm{NF}_{K} B$ and $\mathrm{Sp} 1$ binding motifs to the replicative capacity of human immunodeficiency virus type 1 : distinct patterns of viral growth are determined by T-cell types. J. Virol. 65:4350-4358.

41. Siddiqui, A., R. Gaynor, A. Srinivasan, J. Mapoles, and R. W. Farr. 1989. Trans-activation of viral enhancers including the long terminal repeat of the human immunodeficiency virus by the hepatitis B virus X protein. Virology. 169:479-484.

42. Nelson, C., V. R. Albert, H. P. Elsholtz, L. I. Lu, and M. G. Rosenfeld. 
1988. Activation of cell-specific expression of rat growth hormone and prolactin genes by a common transcription factor. Science (Wash. DC). 239:1400-1405.

43. Rippe, R. A., D. A. Brenner, and H. L. Leffert. 1990. DNA-mediated gene transfer into adult rat hepatocytes in primary culture. Mol. Cell. Biol. 10:689695.

44. Shapiro, D. J., P. A. Sharp, W. W. Wahli, and M. J. Keller. 1988. A high efficiency HeLa cell nuclear transcription extract. DNA (NY). 7:47-55.

45. Lu, Y. C., N. Touzjian, M. Stenzel, T. Dorfman, J. G. Sodroski, and W. A. Haseltine. 1990. Identification of cis-acting repressive sequences within the negative regulatory element of human immunodeficiency virus-type 1. J. Virol. 64:5226-5229.

46. Yahi, N., S. Baghdiguian, H. Moreau, and J. Fantini. 1992. Galactosyl ceramide (or a closely related molecule) is the receptor for human immunodeficiency virus type 1 on human colon epithelial HT29 cells. J. Virol. 66:48484854.

47. Hattori, M., A. Tugores, J. K. Westwick, L. Veloz, H. L. Leffert, M. Karin, and D. A. Brenner. 1992. Activation of AP-1 during the hepatic acute phase response. Am. J. Physiol. 264:G95-G103.

48. Guo, Z. S., and M. L. DePamphilis. 1992. Specific transcription factors stimulate simian virus $\mathbf{4 0}$ and polyomavirus origins of DNA replication. Mol. Cell. Biol. 2:2514-2524.

49. Van Lint, C., A. Burny, and E. Verdin. 1991. The intragenic enhancer of human immunodeficiency virus type 1 contains functional AP1 binding sites. $J$. Virol. 5:7066-7072.

50. Leonard, J., C. Parrott, A. J. Buckler-White, W. Turner, E. K. Ross, M. A. Martin, and A. B. Rabson. 1989. The NFKB binding sites in the immunodeficiency virus type long terminal repeat are not required for virus infectivity. $J$. Virol. 63:4919-4924.

51. Doppler, C., G. Schalasta, E. Amtmann, and G. Sauer. 1992. Binding of NFKB to the HIV-1 LTR is not sufficient to induce HIV-1 LTR activity. AIDS Res. Hum. Retroviruses. 8:245-252.

52. Hazan, U., D. Thomas, J. Alcami, F. Bachelerie, N. Isreal, H. Yssel, J.-L. Virelizier, and F. Arenzana-Seisdedos. 1990. Stimulation of a human T-cell clone with anti-CD3 or tumor necrosis factor induces NF $k B$ translocation but not human immunodeficiency virus 1 enhancer-dependent transcription. Proc. Natl. Acad. Sci. USA. 87:7861-7865.

53. Arya, S. K. 1991. Human immunodeficiency virus type 2 gene expression: downmodulation by sequence elements downstream of the transcription initiation site. AIDS Res. Hum. Retroviruses. 7:1007-1014.

54. Boris-Lawrie, K., J. N. Brady, and A. Kumar. 1992. Sequences within the $R$ region of the long terminal repeat activate basal transcription from the HIV-1 promoter. Gene Expression. 2:215-230.

55. Velcich, A., and E. B. Ziff. 1990. Functional analysis of an isolated fos promoter element with API site homology reveals cell type-specific transcriptional properties. Mol. Cell. Biol. 10:6273-6282.

56. Wilkinson, D. G., S. Bhatt, R. P. Ryseck, and R. Bravo. 1989. Tissue-specific expression of c-jun and junB during organogenesis in the mouse. Development (Camb.). 106:465-471.

57. Wada, T., H. Watanabe, Y. Usuda, and H. Handa. 1991. Different biologi- cal activities of the hetero- and homodimers formed by the 47- and 43-kilodalton proteins of transcription factor ATF/E4TF3. J. Virol. 65:557-564.

58. Cowell, I. G., A. Skinner, and H. C. Hurst. 1992. Transcriptional repression by a novel member of the bZIP family of transcription factors. Mol. Cell. Biol. 12:3070-3077.

59. Karprinski, B. A., G. D. Morle, J. Huggenvik, M. D. Uhler, and J. M. Leiden. 1992. Molecular cloning of human CREB-2: an ATF/CREB transcription factor that can negatively regulate transcription form the cAMP response element. Proc. Natl. Acad. Sci. USA. 89:4820-4824.

60. Jeang, K.-T., R. Chiu, E. Santos, and S.-J. Kim. 1991. Induction of the HTLV-1 LTR by Jun occurs through the Tax-responsive 21-bp elements. Virology. 181:218-227.

61. Maurer, B., E. Serfling, V. Ter Meulen, and A. Rethwilm. 1991. Transcription factor AP1 modulates the activity of the human foamy virus long terminal repeat. $J$. Virol. 65:6553-6357.

62. Willems, L., R. Kettmann, G. Chen, D. Portetelle, A. Burny, and D. Derse. 1991. A cyclic AMP-responsive DNA-binding protein (CREB2) is a cellular transactivator of the bovine leukemia virus long terminal repeat. J.Virol. 66:766-771.

63. Sparger, E. E., B. L. Shacklett, L. Renshaw-Gegg, P. A. Barry, N. C. Pedersen, J. H. Elder, and P. A. Luciw. 1992. Regulation of gene expression directed by the long terminal repeat of the feline immunodeficiency virus. Virology. 187:165-177.

64. Mallon, R., J. Borkowski, R. Albin, S. Pepitoni, J. Schwartz, and E. Kieff. 1990. The Epstein-Barr virus BZLF1 gene product activates the human immunodeficiency virus type $15^{\prime}$ long terminal repeat. J. Virol. 64:6282-6285.

65. Maguire, H. F., J. P. Hoeffler, and A. Siddiqui. 1991. HBV X protein alters the DNA binding specificity of CREB and ATF- 2 by protein-protein interactions. Science (Wash. DC). 252:842-844.

66. Delmas, V., B. M. Laoide, D. Masquilier, R. P. De Groot, N. S. Foulkes, and P. Sassone-Corsi. 1992. Alternative usage of initiation codon in mRNA encoding the CAMP responsive element modulator generates regulators with opposite functions. Proc. Natl. Acad. Sci. USA. 89:4226-4230.

67. Nakanishi, Y., Y. Masamune, and N. Kobayashi. 1991. A novel cis-acting element that controls transcription of human immunodeficiency virus type 1 DNA, depending on cell type. J. Virol. 65:6334-6338.

68. Auwerx, J., and P. Sassone-Corsi. 1991. IP-1: a dominant inhibitor of fos/jun whose activity is modulated by phosphorylation. Cell. 64:983-993.

69. Xanthoudakis, S., and T. Curran. 1992. Identification and characterization of Ref-1, a nuclear protein that facilitates AP-1 DNA binding activity. EMBO (Eur. Mol. Biol. Organ.) J. 11:653-665.

70. Ono, S. J., H.-C. Liou, R. Davidon, J. L. Strominger, and L. H. Glimcher. 1991. Human X-box-binding protein 1 is required for the transcription of subset of human class II major histocompatibility genes and forms a heterodimer with c-fos. Proc. Natl. Acad. Sci. USA. 88:4309-4312.

71. Spergel, J. M., W. Hsu, S. Akira, B. Thimmappaya, T. Kishimoto, and S. Chen-Kiang. 1992. NF-IL6, a member of the C/EBP family, regulates E1A-responsive promoters in the absence of E1A. J. Virol. 66:1021-1030. 